Check for updates

Cite this: RSC Adv., 2018, 8, 39641

Received 18th October 2018 Accepted 21st November 2018

DOI: $10.1039 / c 8 r a 08643 e$

rsc.li/rsc-advances

\section{Magnetic solid-phase extraction using a mixture of two types of nanoparticles followed by gas chromatography-mass spectrometry for the determination of six phthalic acid esters in various water samples $\dagger$}

\author{
Hui Li, ${ }^{a}$ Zhen Cao, (D) *a Xiaolin Cao, ${ }^{a}$ Zejun Jiang, ${ }^{a}$ A. M. Abd El-Aty, ${ }^{\text {bc }}$ Yan Qi, ${ }^{a}$ \\ Hua Shao, ${ }^{a}$ Fen Jin, ${ }^{a}$ Lufei Zheng ${ }^{a}$ and Jing Wang ${ }^{a}$
}

Two types of magnetic microspheres $\left(\mathrm{Fe}_{3} \mathrm{O}_{4} @ \mathrm{MIL}-100\right.$ and $\mathrm{Fe}_{3} \mathrm{O}_{4}\left(\mathrm{SSiO}_{2} @\right.$ polythiophene) were prepared and characterized as mixed sorbents for magnetic solid-phase extraction (MSPE) of six phthalic acid esters (PAEs), including dimethyl phthalate (DMP), diethyl phthalate (DEP), di- $n$-butyl phthalate (DBP), benzyl butyl phthalate (BBP), di-2-ethylhexyl phthalate (DEHP), and di-n-octyl phthalate (DnOP) from water samples prior to gas chromatography-mass spectrometry (GC-MS) analysis. The synthetic magnetic nanocomposites exhibited good repeatability and chemical stability, and improved extraction efficiency for the tested PAEs. The mixture of the two types of nanoparticles substantially improved the extraction efficiency of both DMP and DEP. The key parameters affecting the extraction efficiency, such as the type and the amount of sorbent, eluent (desorption solvent), adsorption and desorption time, pH of sample solution, and sample volume, were investigated and optimized, respectively. Under optimized conditions, the developed method showed satisfactory linearity in the range of $5-5000 \mu \mathrm{g} \mathrm{L}^{-1}$ with coefficients of determination $\left(R^{2}\right)>0.9935$. The method detection limits (MDLs) and limits of quantitation (LOQs) were between $0.35-0.91 \mu \mathrm{g} \mathrm{L^{-1 }}$ and $1.1-2.9 \mu \mathrm{g} \mathrm{L}^{-1}$, respectively. At three fortification levels $\left(1.0,10.0\right.$, and $50.0 \mu \mathrm{g} \mathrm{L}^{-1}$ ), the mean recoveries ranged from $76.9-109.1 \%$ with favorable relative standard deviations (RSDs) $<9 \%$. The feasibility of the method was evaluated by analysis of water samples from various sources (tap, drinking, and mineral water). The results show that the developed method is suitable for determination of trace level PAEs in water samples.

\section{Introduction}

Phthalic acid esters (PAEs) are primarily used as plasticizers in the manufacture of plastics, children's toys, medical devices, food packaging materials, and other plastic products, to improve their flexibility, elasticity, and processability. ${ }^{1-3}$ PAEs are not tightly bound to the polymers ${ }^{1}$ and they can be easily leached into food or water. A series of studies have revealed that PAEs might cause teratogenic, carcinogenic, reproductive and developmental effects, and endocrine disruption in animals., ${ }^{2,45}$ With their

${ }^{a}$ Institute of Quality Standard and Testing Technology for Agro-products, Chinese Academy of Agricultural Sciences, Key Laboratory of Agro-product Quality and Safety, Ministry of Agriculture, Beijing, 100081, P. R. China. E-mail: caozhen01@ caas.cn; Fax: +86-10-82106568; Tel: +86-010-82106513

${ }^{b}$ Department of Pharmacology, Faculty of Veterinary Medicine, Cairo University, 12211 Giza, Egypt

'Department of Medical Pharmacology, Medical Faculty, Ataturk University, Erzurum 25240, Republic of Turkey

† Electronic supplementary information (ESI) available. See DOI: 10.1039/c8ra08643e extensive uses, PAEs might pose a potential risk to human health. It is therefore important to develop an effective and reliable quantitative method for determination of PAEs at trace level.

Considering the relatively low concentration of PAEs in real samples, sample pretreatment and enrichment procedures are normally necessary prior to their chromatographic analysis. To date, solid-phase extraction (SPE) ${ }^{6-8}$ and solid-phase microextraction (SPME) ${ }^{9-11}$ are commonly used as prior sample pretreatment for PAEs detection. However, SPE is somewhat time-consuming and may suffer from blockage of the cartridges $^{2,12}$ that may lead to extraction failure. High cost, fragility, and poor chemical and thermal stabilities of SPME fibers limit its extensive application in the SPME method. ${ }^{1,12}$ To overcome the aforementioned pitfalls, a new mode of SPE, namely magnetic solid-phase extraction (MSPE), has been introduced as a promising extraction approach. Magnetic sorbents, the core of MSPE, exhibit excellent extraction efficiency and can be easily and rapidly isolated from the mixture solution using an external magnetic field. Various functionalized magnetic nanomaterials have been fabricated and used as 
an appropriate sorbent in MSPE techniques. For instance, magnetic covalent triazine frameworks/Ni (CTFs/Ni) composites with good thermal and chemical stability were prepared and used to develop a MSPE method for the analysis of 6 PAEs (DMP, DEP, DBP, BBP, DEHP and DnOP) in plastic packaging material. ${ }^{1}$ The developed method was simple, sensitive, and consumed less organic solvents. Meanwhile, Xu et al. ${ }^{\mathbf{1 2}}$ synthesized $\mathrm{Fe}_{3} \mathrm{O}_{4} @$ silica@triblock-copolymer magnetic microspheres as MSPE sorbents for detecting the same 6 PAEs analytes in apparel textile. The aforementioned studies fail to extract both DMP and DEP with satisfactory extraction efficiency because of their weaker hydrophobic interaction with synthesized composites, which makes them unsuitable for better quantification of both DMP and DEP.

Recently, metal-organic frameworks (MOFs) combined with the magnetic core $\left(\mathrm{Fe}_{3} \mathrm{O}_{4}\right)$ have successfully been synthesized and attracted much attention as efficient sorbents in MSPE. It has to be noted that $\mathrm{Fe}_{3} \mathrm{O}_{4} @ M I L-100$ has a promising application in analysis of environmental organic pollutants. In this context, Chen and co-workers ${ }^{\mathbf{1 3}}$ designed and synthesized magnetic $\mathrm{Fe}_{3} \mathrm{O}_{4} @ \mathrm{MIL}-100$ (Fe) core-shell microspheres as sorbents for the MSPE of polychlorinated biphenyls (PCBs) from environmental water samples. Their results demonstrated that the prepared composites exhibited good extraction efficiency for the tested analytes owing to $\pi-\pi$ interaction. Considering PAEs having benzene rings (same as PCBs), the $\mathrm{Fe}_{3} \mathrm{O}_{4} @ M I L-100$ (Fe) composite might be applicable for the extraction of PAEs with the same mode of $\pi-\pi$ interaction.

Except for magnetic MOFs composites, magnetic nanoparticles (NPs) modified and functionalized by polymers are considered attractive alternative sorbents for MSPE of organic pollutants. Among functionalized polymer sorbents, much attention has been recently paid to polythiophene (PT) due to its high hydrothermal stability. ${ }^{\mathbf{1 4}}$ PT has several double bonds that can interact with pollutants containing benzene rings through $\pi-\pi$ interaction. Mehdinia et al. ${ }^{14}$ synthesized graphene/ $\mathrm{Fe}_{3}-$ $\mathrm{O}_{4}$ @polythiophene $\left(\mathrm{G} / \mathrm{Fe}_{3} \mathrm{O}_{4} @ \mathrm{PT}\right)$ nanocomposite as a MSPE sorbent for determination of five polycyclic aromatic hydrocarbons (PAHs) in environmental water samples. Furthermore, Tahmasebi and co-workers ${ }^{15}$ prepared polythiophene-coated $\mathrm{Fe}_{3} \mathrm{O}_{4}$ nanoparticles $\left(\mathrm{Fe}_{3} \mathrm{O}_{4} @ \mathrm{PT}\right.$ NPs) to extract three type of PAEs, including DBP, DEHP, and dioctyl adipate (DOA) from environmental water samples. However, the synthetic procedure of $\mathrm{G} / \mathrm{Fe}_{3} \mathrm{O}_{4} @ \mathrm{PT}$ was complicated and time-consuming.

The current study was aimed to synthesize both $\mathrm{Fe}_{3} \mathrm{O}_{4} @ \mathrm{MIL}-$ 100 and $\mathrm{Fe}_{3} \mathrm{O}_{4} @ \mathrm{SiO}_{2} @ \mathrm{PT}$ and use the mixture of magnetic NPs as MSPE sorbents for the extraction of 6 PAEs, including DMP, DEP, DBP, BBP, DEHP, and DnOP, prior to GC-MS analysis. This mixture was used to improve the extraction efficiency of both DMP and DEP. The principal parameters affecting extraction efficiencies were optimized, and the performance parameters of the developed method were also evaluated. To prove the feasibility, the developed method was finally applied to determine the target PAEs in various water samples. To the best of our knowledge, the stable and effective silica-coated NPs with surface grafting by $\mathrm{PT}\left(\mathrm{Fe}_{3} \mathrm{O}_{4} @ \mathrm{SiO}_{2} @ \mathrm{PT}\right)$ were synthesized and characterized for the first time herein for the extraction of PAEs.

\section{Materials and methods}

\subsection{Reagents and materials}

Ferric chloride hexahydrate $\left(\mathrm{FeCl}_{3} \cdot 6 \mathrm{H}_{2} \mathrm{O}\right)$ and benzene-1,3,5tricarboxylic acid $\left(\mathrm{H}_{3} \mathrm{BTC}\right)$ were purchased from Sigma Aldrich (St. Louis, MO, US). Ferrous chloride tetrahydrate $\left(\mathrm{FeCl}_{2} \cdot 4 \mathrm{H}_{2} \mathrm{O}\right)$ was obtained from Xi Long Chemical Co., Ltd. (Guangdong, China). Methylacrylic acid (MAA), tetraethyl orthosilicate (TEOS), and thiophene were supplied by Aladdin Industrial Corporation (Shanghai, China). Ammonia solution $(25 \%$, w/w) was purchased from Macklin Biochemical Co., Ltd. (Shanghai, China). Analytical grade ethanol and trichloromethane were provided by Beijing Chemical Works (Beijing, China). LC grade acetonitrile (ACN) and hexane were acquired from Fisher Scientific (Pittsburgh, USA). DMP (99.5\% purity), DEP (99.5\% purity), DBP (99.4\% purity), BBP (98.4\% purity), DEHP (99.6\% purity), and DnOP (99.5\% purity) were supplied by Dr Ehrenstorfer GmbH (Augsburg, Germany).

The standard stock solutions $\left(1.0 \mathrm{mg} \mathrm{mL}^{-1}\right)$ of the tested PAEs were prepared by reconstituting the appropriate amount of each tested analyte in ACN and stored at $4{ }^{\circ} \mathrm{C}$ in dark. Working solutions were prepared daily by appropriate dilution with ACN. To minimize the risk of xenobiotic phthalate contamination, all solvents were examined for the presence of phthalates before use.

\subsection{GC-MS}

A SHIMADZU TQ-8040 (Kyoto, Japan) GC-MS system equipped with an auto-injector (AOC-20i) was used for analysis. Chromatographic separation was conducted on a DB5-MS capillary column $(30 \mathrm{~m} \times 0.25 \mathrm{~mm}$ i.d., $0.25 \mu \mathrm{m}$ thickness; J\&W Scientific, CA, USA). The temperature of the inlet and MS transfer line was maintained at $280{ }^{\circ} \mathrm{C}$. The injection was performed in a splitless mode. The oven temperature was initially set at $60{ }^{\circ} \mathrm{C}$ for $1 \mathrm{~min}$, programmed to $240{ }^{\circ} \mathrm{C}$ at $30^{\circ} \mathrm{C} \mathrm{min}{ }^{-1}$, held for $2 \mathrm{~min}$, and finally increased to $270{ }^{\circ} \mathrm{C}$ at $5{ }^{\circ} \mathrm{C} \min ^{-1}$ and held for $5 \mathrm{~min}$. Helium carrier gas (purity $\geq 99.999 \%$ ) was maintained at a constant flow rate of $1.03 \mathrm{~mL} \mathrm{~min}^{-1}$. A sample injection volume of $1 \mu \mathrm{L}$ was used for each run and the solvent delay was set to $5 \mathrm{~min}$. Quantitative analysis was performed in selected ion monitoring (SIM) mode. Detailed analytical parameters such as retention time and SIM transition are compiled in Table 1.

\subsection{Synthesis of magnetic microspheres}

(a) Preparation of $\mathrm{Fe}_{3} \mathrm{O}_{4} @ M I L-100 \quad$ (Fe) core-shell magnetic microspheres. $\mathrm{Fe}_{3} \mathrm{O}_{4}$ nanoparticles were synthesized with a chemical coprecipitation method according to our

Table 1 GC-MS parameters for the tested PAEs

\begin{tabular}{lcll}
\hline Compound & Retention time (min) & Target ion & Qualifier ions \\
\hline DMP & 7.098 & 163 & 133,77 \\
DEP & 8.450 & 149 & 177,176 \\
DBP & 9.035 & 149 & 205,150 \\
BBP & 12.490 & 149 & 206,91 \\
DEHP & 14.520 & 149 & 167,57 \\
DnOP & 17.275 & 149 & 279,150
\end{tabular}


previous protocol. ${ }^{16}$ First, $\mathrm{FeCl}_{3} \cdot 6 \mathrm{H}_{2} \mathrm{O}(2.35 \mathrm{~g})$ and $\mathrm{FeCl}_{2} \cdot 4 \mathrm{H}_{2} \mathrm{O}$ $(0.86 \mathrm{~g})$ were dissolved in $100 \mathrm{~mL}$ of deionized water with stirring at $70{ }^{\circ} \mathrm{C}$. Then, $25 \%$ ammonia solution $(10 \mathrm{~mL})$ was added, and the mixture was stirred vigorously for $30 \mathrm{~min}$ at $80{ }^{\circ} \mathrm{C}$. Finally, the reaction product was collected with an external magnetic field and then washed several times with deionized water and ethanol.

$\mathrm{Fe}_{3} \mathrm{O}_{4} @$ MIL-100 core-shell was synthesized as reported previously ${ }^{13}$ Briefly, $0.10 \mathrm{~g}$ of $\mathrm{Fe}_{3} \mathrm{O}_{4}$ NPs was dispersed in $20 \mathrm{~mL}$ of MAA ethanol solution $(0.58 \mathrm{mM})$ with ultrasonication for $5 \mathrm{~min}$ and then shaking for $24 \mathrm{~h}$ at room temperature. The precipitate was isolated from the solution by an external magnetic field and washed several times with deionized water and ethanol. Then, the NPs $(0.10 \mathrm{~g})$ synthesized above was dissolved in $5 \mathrm{~mL}$ of $\mathrm{FeCl}_{3} \cdot 6 \mathrm{H}_{2} \mathrm{O}$ ethanol solution $(10 \mathrm{mM})$ for $15 \mathrm{~min}$ and then in $5 \mathrm{~mL}$ of $\mathrm{H}_{3} \mathrm{BTC}$ ethanol solution $(10 \mathrm{mM})$ for $30 \mathrm{~min}$ at $70{ }^{\circ} \mathrm{C}$. Finally, the product was washed several times with ethanol and dried at $60^{\circ} \mathrm{C}$ for $24 \mathrm{~h}$.

(b) Preparation of $\mathrm{Fe}_{3} \mathrm{O}_{4} @ \mathrm{SiO}_{2} @ \mathrm{PT}$ nanocomposites. $\mathrm{Fe}_{3} \mathrm{O}_{4}$ NPs were synthesized as described above, ${ }^{16}$ and $\mathrm{Fe}_{3}-$ $\mathrm{O}_{4} @ \mathrm{SiO}_{2}$ nanoparticles were synthesized according to the method described by Synaridou et al. ${ }^{17}$ with minor modifications. Briefly, $\mathrm{Fe}_{3} \mathrm{O}_{4}$ NPs $(1 \mathrm{~g})$ were dispersed in a mixture containing $25 \mathrm{~mL}$ of ethanol and $8 \mathrm{~mL}$ of deionized water under ultrasonication for $5 \mathrm{~min}$. Afterward, $500 \mu \mathrm{L}$ of TEOS and $1 \mathrm{~mL}$ of $25 \%$ ammonia were added and homogenously dispersed in the above solution for $5 \mathrm{~min}$. The reaction mixtures were vigorously stirred for $12 \mathrm{~h}$ at room temperature. Finally, the sediments were rinsed several times with ethanol and dried for $24 \mathrm{~h}$ at $60{ }^{\circ} \mathrm{C}$.
The $\mathrm{Fe}_{3} \mathrm{O}_{4} @ \mathrm{SiO}_{2} @ \mathrm{PT}$ nanocomposites were prepared via adding $0.3 \mathrm{~g}$ of $\mathrm{Fe}_{3} \mathrm{O}_{4} @ \mathrm{SiO}_{2}, 1.0 \mathrm{~g}$ of anhydrous $\mathrm{FeCl}_{3}$, and $0.25 \mathrm{~g}$ of thiophene to $55 \mathrm{~mL}$ of chloroform, respectively. The mixtures were stirred for $6 \mathrm{~h}$ at room temperature. Thereafter, the microspheres were separated by an ordinary magnet, washed several times with ethanol, and then dried for $24 \mathrm{~h}$ at $60{ }^{\circ} \mathrm{C}$.

\subsection{MSPE procedure}

Thirty microgram of magnetic nanoparticles $\left(15 \mathrm{mg}\right.$ of $\mathrm{Fe}_{3} \mathrm{O}_{4} @$ @MIL-100 and 15 mg of $\mathrm{Fe}_{3} \mathrm{O}_{4} @ \mathrm{SiO}_{2} @ \mathrm{PT}$ ) were added into a glass vial containing $10 \mathrm{~mL}$ of water solution $(\mathrm{pH}=6)$. Using ultrasonication, the mixture was homogenously dispersed in the aqueous phase for $1 \mathrm{~min}$, and then the solution was shaken in an oscillator at $200 \mathrm{rpm}$ for $15 \mathrm{~min}$. The sorbents were separated from the aqueous phase by an external magnet and the supernatant was discarded. Afterward, $1 \mathrm{~mL}$ of ACN was added and shaken for $10 \mathrm{~min}$. The solution was collected by magnetic separation and then evaporated to dryness under a mild nitrogen stream at room temperature. At last, the residue was dissolved in $200 \mu \mathrm{L}$ of hexane and filtered through a $0.22 \mu \mathrm{m}$ glass membrane into a glass autosampler vial for GC-MS analysis.

\section{Results and discussion}

\subsection{Characterization of the magnetic $\mathrm{Fe}_{3} \mathrm{O}_{4} @ \mathrm{MIL}-100$ and $\mathrm{Fe}_{3} \mathrm{O}_{4} @ \mathrm{SiO}_{2} @ \mathrm{PT}$ composites}

The morphologies of synthesized microspheres were characterized by transmission electron microscopy (TEM) (JEOL-JEM2100F, Japan). As shown in Fig. 1a, the $\mathrm{Fe}_{3} \mathrm{O}_{4}$ core was coated by
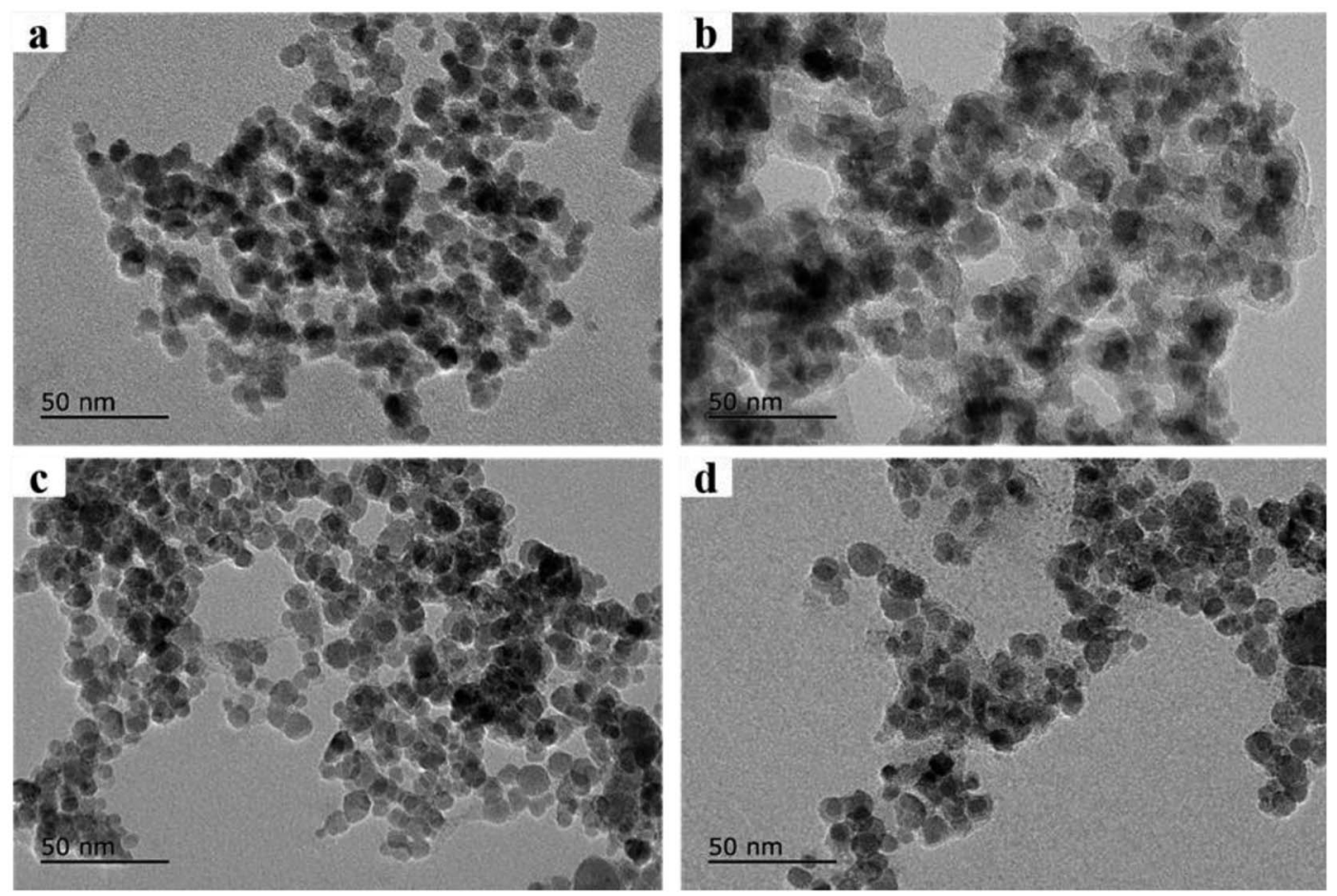

Fig. 1 Transmission Electron Microscope images of prepared nano-materials. (a) $\mathrm{Fe}_{3} \mathrm{O}_{4} \mathrm{QSiO}_{2}, \mathrm{Fe}_{3} \mathrm{O}_{4}$ core was coated by a $\mathrm{SiO} 2$ shell with approximately $10 \mathrm{~nm}$ in thickness, (b) $\mathrm{Fe}_{3} \mathrm{O}_{4} \mathrm{QSiO}_{2} \mathrm{QPT}$, (c) $\mathrm{Fe}_{3} \mathrm{O}_{4} \mathrm{QMIL}-100$, the MOF layer was about $10 \mathrm{~nm}$ of thickness, (d) the mixture of $\mathrm{Fe}_{3} \mathrm{O}_{4} \mathrm{QSiO}{ }_{2} \mathrm{QPT}$ and $\mathrm{Fe}_{3} \mathrm{O}_{4} \mathrm{QMIL}-100$ recycled after one use. 
a $\mathrm{SiO}_{2}$ shell with approximately $10 \mathrm{~nm}$ in thickness. Fig. 1b showed evenly distributed transparent materials on the surface of $\mathrm{Fe}_{3} \mathrm{O}_{4} @ \mathrm{SiO}_{2}$ composites, which indicated the formation of $\mathrm{Fe}_{3} \mathrm{O}_{4} @ \mathrm{SiO}_{2} @ \mathrm{PT}$ core-shell composites. The synthetic magnetic composites were composed of a $\mathrm{Fe}_{3} \mathrm{O}_{4}$ core and a MOF layer in $10 \mathrm{~nm}$ of thickness as shown in Fig. 1c. The mixture of the two sorbents $\mathrm{Fe}_{3} \mathrm{O}_{4} @ \mathrm{MIL}-100$ and $\mathrm{Fe}_{3} \mathrm{O}_{4} @ \mathrm{SiO}_{2} @ \mathrm{PT}$ (recycled after one use) dispersed uniformly as shown in the TEM image (Fig. 1d).

Sufficient magnetic properties are crucial for magnetic sorbents to be effectively separated in aqueous solutions. The magnetic curves of $\mathrm{Fe}_{3} \mathrm{O}_{4} @ \mathrm{MIL}-100$ and $\mathrm{Fe}_{3} \mathrm{O}_{4} @ \mathrm{SiO}_{2} @ \mathrm{PT}$ composites (Fig. 2A) were assessed by vibrating sample magnetometer (VSM). The curve of $\mathrm{Fe}_{3} \mathrm{O}_{4} @$ @IL-100 exhibited no magnetic hysteresis loop, which indicates superparamagnetic properties of $\mathrm{Fe}_{3} \mathrm{O}_{4} @ \mathrm{MIL}-100,{ }^{13}$ while the curve of $\mathrm{Fe}_{3} \mathrm{O}_{4} @ \mathrm{SiO}_{2} @ \mathrm{PT}$ showed slight hysteresis (Fig. 2A). Both composites clearly display strong magnetic properties with saturation magnetization values of 62.0 and $38.2 \mathrm{emu} \mathrm{g}^{-1}$, respectively. And both values of the saturation magnetization are sufficient for separation of the composites by a magnet. ${ }^{18}$ In this study, the obtained magnetic composites were collected by a magnet within $5 \mathrm{~s}$ in aqueous solutions. This results indicate that the mixed magnetic microspheres are suitable for magnetic separation.

Fourier transform infrared (FTIR) spectra of the synthesized microspheres were obtained over the wave number range from 500 to $4000 \mathrm{~cm}^{-1}$ on a PerkinElmer Spectrum 100 FTIR spectrometer (Waltham, MA, US) using the nujol mull method. The characteristic peaks at 3400 and $1634 \mathrm{~cm}^{-1}$ are attributed to the O-H stretching bands (Fig. 2B-a), while the band at $1068 \mathrm{~cm}^{-1}$ was correspondent to the $\mathrm{Si}-\mathrm{O}-\mathrm{Si}$ vibration, ${ }^{17}$ and the peak at $570 \mathrm{~cm}^{-1}$ was assigned to the $\mathrm{Fe}-\mathrm{O}-\mathrm{Fe}$ stretching of $\mathrm{Fe}_{3} \mathrm{O}_{4}$. These indicate that the $\mathrm{SiO}_{2}$ shell has been successfully coated on the surface of $\mathrm{Fe}_{3} \mathrm{O}_{4}$. In contrast to $\mathrm{Fe}_{3} \mathrm{O}_{4} @ \mathrm{SiO}_{2}$, the spectrum of $\mathrm{Fe}_{3} \mathrm{O}_{4} @ \mathrm{SiO}_{2} @ \mathrm{PT}$ exhibits additional peaks, which are related to PT coating (Fig. 2B-b). More specifically, the adsorption peaks at $1423 \mathrm{~cm}^{-1}$ and $1100 \mathrm{~cm}^{-1}$ were assigned to the vibration of $\mathrm{C}=\mathrm{C}$ stretching and $\mathrm{C}-\mathrm{H}$ aromatic bonds of thiophene ring, respectively (Fig. 2B-b). ${ }^{15}$ For $\mathrm{Fe}_{3} \mathrm{O}_{4} @$ @IL-100 (Fig. 2B-d), a band at $570 \mathrm{~cm}^{-1}$ was associated with $\mathrm{Fe}-\mathrm{O}-\mathrm{Fe}$ stretching of $\mathrm{Fe}_{3} \mathrm{O}_{4}$, whereas the other adsorption peaks are linked with the structure of MIL-100. For instance, a peak appeared at $1700 \mathrm{~cm}^{-1}$ was attributed to $\mathrm{C}=\mathrm{O}$ stretching vibration in $\mathrm{H}_{3}$ BTC. The characteristic peaks at $1445 \mathrm{~cm}^{-1}$ and $1374 \mathrm{~cm}^{-1}$ were allocated to both asymmetric and symmetric stretching of carboxyl groups in $\mathrm{H}_{3} \mathrm{BTC}$, respectively. ${ }^{16}$ This result further confirms the formation of a MIL-100 layer on the surface of $\mathrm{Fe}_{3} \mathrm{O}_{4}$. Fig. 2B-c showed the spectra of the mixture of $\mathrm{Fe}_{3} \mathrm{O}_{4} @ \mathrm{MIL}-100$ and $\mathrm{Fe}_{3} \mathrm{O}_{4} @ \mathrm{SiO}_{2} @ \mathrm{PT}$ (recycled after one use), with all characteristic peaks for both NPs.

\subsection{Optimization of the MSPE procedure}

To obtain satisfactory extraction efficiencies for the tested PAEs using MSPE, the main factors, including the type and amount of sorbents, eluents, adsorption and desorption time, $\mathrm{pH}$ conditions, and sample volume, were systematically evaluated by spiking $10 \mu \mathrm{g} \mathrm{L^{-1 }}$ of each tested PAEs in blank drinking water samples.

3.2.1. The types of sorbents. Appropriate sorbent, the core of the MSPE procedure, is pivotal to obtain satisfactory extraction efficiencies. In this study, the effect of the types of sorbents on extraction efficiency was evaluated under some specific extraction conditions $(10 \mathrm{~mL}$ of drinking water at $\mathrm{pH} 6.0$, adsorption time $15 \mathrm{~min}$, desorption time $10 \mathrm{~min}$, and elution with $1 \mathrm{~mL}$ of ACN). As PAEs compounds containing a benzene ring and alkyl chains, $\mathrm{Fe}_{3} \mathrm{O}_{4} @ M I L-100$ NPs were initially expected to be an efficient sorbent based on the possible $\pi-\pi$ stacking and/or hydrophobic interactions. However, poor extraction efficiencies for both DMP and DEP were obtained when $30 \mathrm{mg}$ of $\mathrm{Fe}_{3} \mathrm{O}_{4}$ @MIL-100 NPs were utilized (Fig. 3), which is in line with previous reports. ${ }^{\mathbf{1 , 1 2}}$ This finding is attributed to the higher water solubility of DMP and DEP, and their weaker hydrophobic interaction with $\mathrm{Fe}_{3} \mathrm{O}_{4} @$ MIL-100 NPs. Subsequently, $\mathrm{Fe}_{3} \mathrm{O}_{4} @ \mathrm{SiO}_{2} @ \mathrm{PT}$ composites were investigated. As shown in Fig. 3, all target PAEs showed satisfactory recoveries except DnOP, when $30 \mathrm{mg}$ of $\mathrm{Fe}_{3} \mathrm{O}_{4}$ @SiO $\mathrm{Si}_{2}$ @PT composites were used as MSPE sorbents. The poor recovery of DnOP might be due to its longer alkyl chains that may have a negative effect on the $\pi-\pi$ interaction between the analyte and the sorbent. When $30 \mathrm{mg}$ of the mixture $\left(\mathrm{Fe}_{3} \mathrm{O}_{4} @ \mathrm{MIL}-100: \mathrm{Fe}_{3} \mathrm{O}_{4} @ \mathrm{SiO}_{2} @ \mathrm{PT}=\right.$
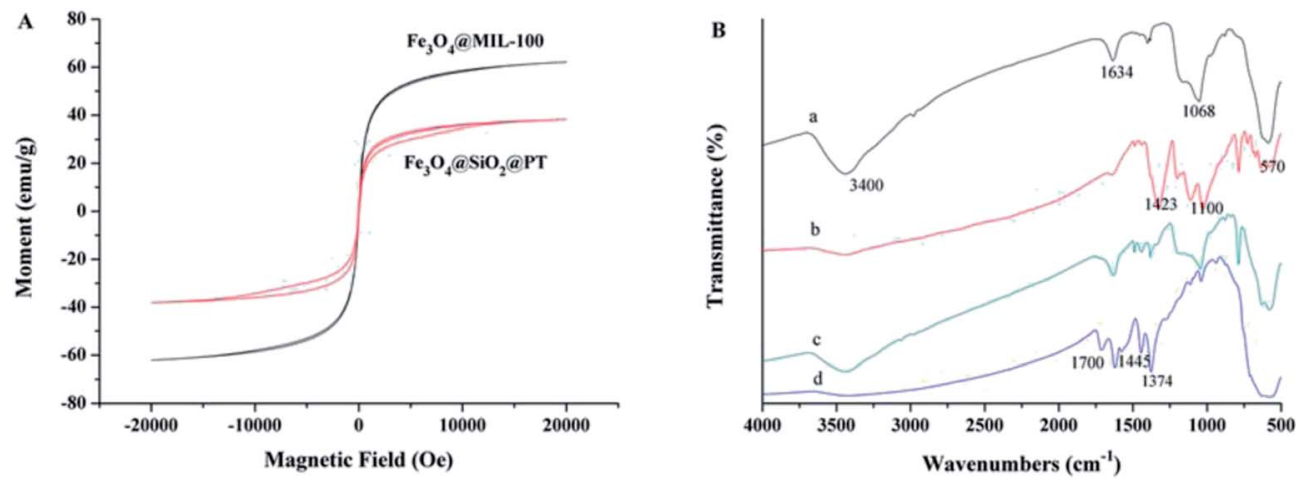

Fig. 2 Characterization of prepared nano-materials, (A) magnetic curves of prepared two composites, and (B) the FTIR spectra of (a) Fe $3^{-}$ $\mathrm{O}_{4} @ \mathrm{SiO}_{2}$, (b) $\mathrm{Fe}_{3} \mathrm{O}_{4} @ \mathrm{SSiO}_{2} \mathrm{aPT}$, (c) the mixture recycled after one use, and (d) $\mathrm{Fe}_{3} \mathrm{O}_{4} @ \mathrm{MMIL}-100$. 


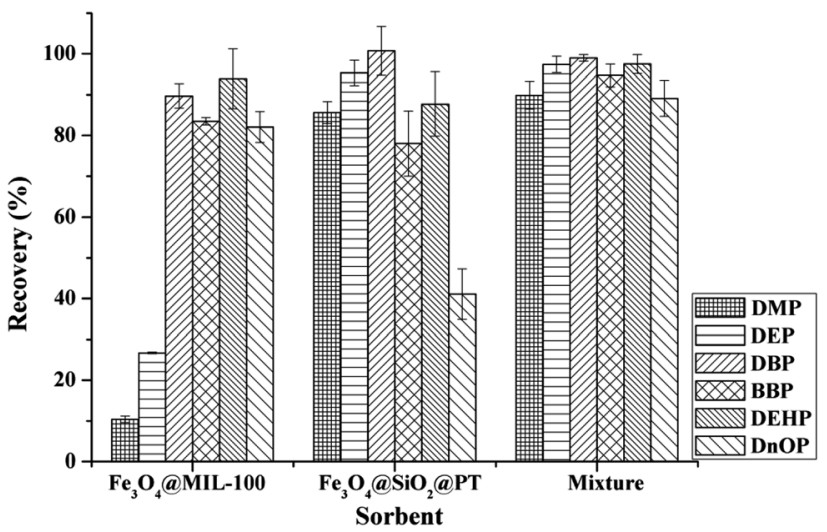

Fig. 3 Extraction efficiency of six phthalic acid esters with composites $\mathrm{Fe}_{3} \mathrm{O}_{4} \mathrm{aSiO}_{2} \mathrm{aPT}, \mathrm{Fe}_{3} \mathrm{O}_{4} \mathrm{aMIL}-100$ and the mixture of $\mathrm{Fe}_{3} \mathrm{O}_{4} \mathrm{aSiO}_{2} \mathrm{a}$ $\mathrm{PT}$ and $\mathrm{Fe}_{3} \mathrm{O}_{4} \mathrm{QMIL}-100$, respectively. Extraction conditions: $10 \mathrm{~mL}$ of spiked drinking water at $10.0 \mu \mathrm{g} \mathrm{L}^{-1}, 30 \mathrm{mg}$ of sorbents, $1 \mathrm{~mL}$ of ACN as elution solvent, $\mathrm{pH}$ 6.0, adsorption time $15 \mathrm{~min}$, and desorption time $10 \mathrm{~min}$.

$1: 1, \mathrm{w} / \mathrm{w}$ ) was used conjointly for the extraction of the tested PAEs compounds, satisfactory extraction efficiencies (over 90\%) were obtained for each analyte (Fig. 3). As the results, the mixture of $\mathrm{Fe}_{3} \mathrm{O}_{4} @ M I L-100$ and $\mathrm{Fe}_{3} \mathrm{O}_{4} @ \mathrm{SiO}_{2} @ P T$ was finally chosen for the MSPE process.

3.2.2. The amount of the mixed sorbents. The effect of the amount of the mixed sorbents was explored based on the ratio of $\mathrm{Fe}_{3} \mathrm{O}_{4} @ M I L-100$ and $\mathrm{Fe}_{3} \mathrm{O}_{4} @ \mathrm{SiO}_{2} @ P T(1: 1, \mathrm{w} / \mathrm{w})$ and the total amount of the mixed sorbents of 10, 20, 30, 40 and $50 \mathrm{mg}$ when $10 \mathrm{~mL}$ of drinking water at $\mathrm{pH} 6.0$ was extracted for $25 \mathrm{~min}$ (adsorption time $15 \mathrm{~min}$ and desorption time $10 \mathrm{~min}$ ), and eluted with $1 \mathrm{~mL}$ of ACN. As shown in Fig. 4, the adsorption efficiency of DEP and BBP showed little change with increasing sorbents amount. This finding might indicate that the mixed sorbents had good adsorption performance for the extraction of both DEP and BBP, even small amounts of sorbents achieved satisfactory adsorption. The most satisfactory adsorption

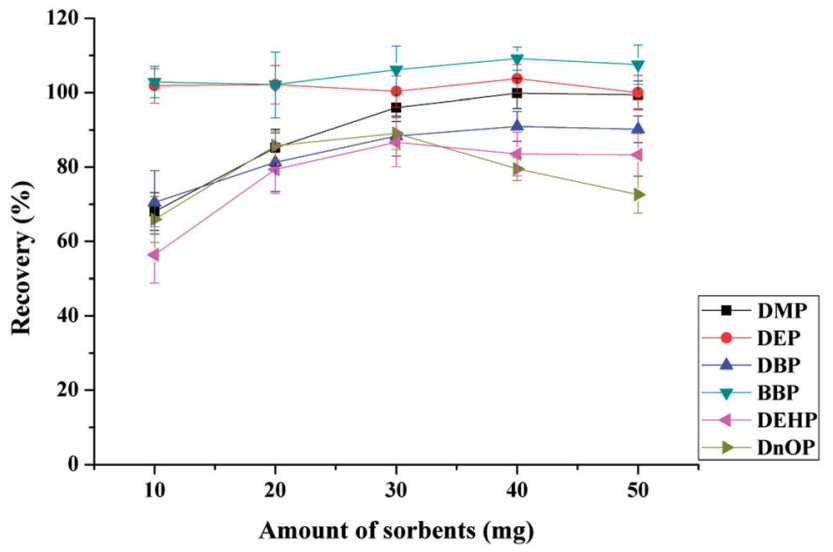

Fig. 4 Extraction efficiency of six phthalic acid esters with different amount of the mixed sorbents. Extraction conditions: $10 \mathrm{~mL}$ of spiked drinking water at $10.0 \mu \mathrm{g} \mathrm{L}^{-1}, 1 \mathrm{~mL}$ of $\mathrm{ACN}$ as elution solvent, $\mathrm{pH}$ 6.0, adsorption time $15 \mathrm{~min}$, desorption time $10 \mathrm{~min}$, and mixed sorbents $\left(\mathrm{Fe}_{3} \mathrm{O}_{4} \mathrm{QMIL}-100: \mathrm{Fe}_{3} \mathrm{O}_{4} \mathrm{aSiO}_{2} \mathrm{QPT}=1: 1, \mathrm{w} / \mathrm{w}\right)$ as the MSPE sorbents. efficiencies (for DBP, BBP, DEHP, and DnOP) were achieved when $30 \mathrm{mg}$ of sorbents were used. However, the adsorption efficiency of DnOP decreased dramatically with further increment of the amount of the mixed sorbents, which might be attributed to the incomplete elution. ${ }^{19}$ Therefore, $30 \mathrm{mg}$ of mixed sorbents $\left(15 \mathrm{mg}\right.$ of $\mathrm{Fe}_{3} \mathrm{O}_{4} @ \mathrm{MIL}-100$ and $15 \mathrm{mg}$ of $\mathrm{Fe}_{3^{-}}$ $\left.\mathrm{O}_{4} @ \mathrm{SiO}_{2} @ \mathrm{PT}\right)$ were selected as the optimal amount for the extraction of the tested PAEs. It's worth noting that higher extraction recovery may be obtained with other mixture ratio of $\mathrm{Fe}_{3} \mathrm{O}_{4} @ \mathrm{MIL}-100 / \mathrm{Fe}_{3} \mathrm{O}_{4} @ \mathrm{SiO}_{2} @$ polythiophene sorbents.

3.2.3. Eluent. To screen suitable eluent for analytes desorption from prepared nanoparticles, $10 \mathrm{~mL}$ of drinking water at $\mathrm{pH} 6.0$ was extracted with $30 \mathrm{mg}$ of mixed sorbents, and eluted with $1.0 \mathrm{~mL}$ of ACN, acetone, ethyl acetate, and hexane were tested, respectively. High recovery rates $(100-150 \%)$ were obtained for all tested analytes (DMP, DEP, DBP, BBP, DEHP, DnOP) with each of the organic solvent (Fig. S1†). The unsatisfactory recoveries (out of the acceptable range, 70-120\%) might be correlated to the super elution power of the three organic solvents, or some unexpected interferences might be coeluted leading to enhancement effect. ${ }^{20}$ In this study, ACN achieved the ideal recoveries (73.4-102.9\%) for tested analytes, and therefore, was chosen as eluent for further experimental work.

3.2.4. $\mathrm{pH}$ value. The $\mathrm{pH}$ value of the sample solution can affect the charges of the tested analytes on adsorbent surface, ${ }^{16,19}$ which further affects the hydrophobic interaction between analytes and adsorbents. Herein, different solution $\mathrm{pH}$ values, in the range of 2-10, were investigated for its effect on extraction efficiencies under the extraction conditions $(10 \mathrm{~mL}$ of drinking water sample, $30 \mathrm{mg}$ of mixed sorbents, $1 \mathrm{~mL}$ of ACN as elution solvent, adsorption time $15 \mathrm{~min}$, and desorption time $10 \mathrm{~min})$. As shown in Fig. S2, $\dagger$ all tested analytes have shown acceptable extraction recoveries (77.4-115.1\%) with $\mathrm{pH}$ value from 2 to 10, which indicated that the synthetic sorbents had good $\mathrm{pH}$ stability. In general, the extraction recoveries of DBP, $\mathrm{BBP}, \mathrm{DEHP}$, and DnOP were gradually increased when the $\mathrm{pH}$ value increased from 2 to 6 , and remain unchanged with further $\mathrm{pH}$ value increment up to 10 . Based on the findings, $\mathrm{pH}$ value 6 was selected for extraction and enrichment of the tested PAEs using the mixed sorbents.

3.2.5. Length of adsorption and desorption time. Length of adsorption time plays a vital role for the extraction efficiencies of analytes in MSPE procedure. In the present study, $10 \mathrm{~mL}$ of drinking water at $\mathrm{pH} 6.0$ was extracted with $30 \mathrm{mg}$ of mixed sorbents, and eluted with $1.0 \mathrm{~mL}$ of ACN. In this case, adsorption times were investigated in the range of 5-30 min (Fig. S3 †). It was found that the adsorption time had a minimal effect on the extraction efficiency of DMP, DEP, DBP, and BBP. Most of the analytes could be adsorbed onto the mixed $\mathrm{Fe}_{3} \mathrm{O}_{4} @$ MIL-100 and $\mathrm{Fe}_{3} \mathrm{O}_{4} @ \mathrm{SiO}_{2} @ \mathrm{PT}$ nanocomposite within $5 \mathrm{~min}$, which might suggest that the mixed adsorbents had a strong extraction power for the 4 tested PAEs. With 15 min adsorption time, the best recoveries for DEHP and DnOP were obtained. Thereby, the adsorption time was selected to be $15 \mathrm{~min}$. Length of desorption time is another key parameter in MSPE process. It is expected that analytes can be fully eluted within a short time. In 


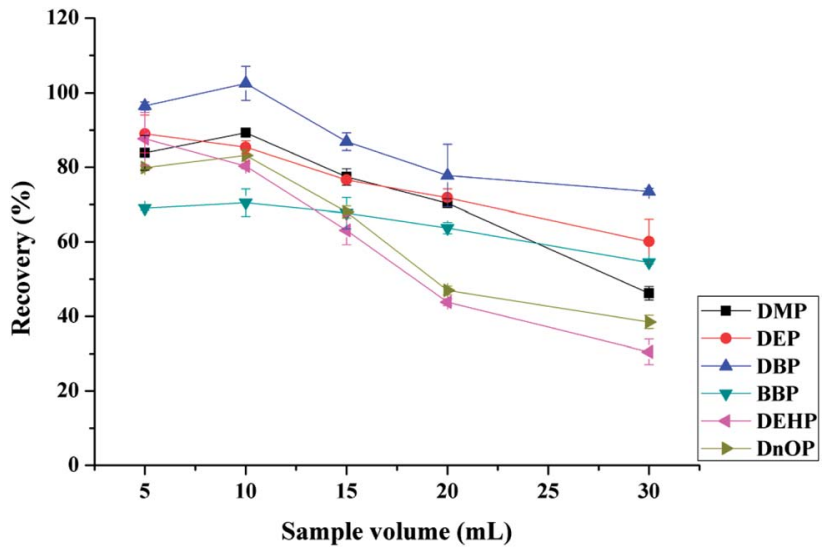

Fig. 5 Extraction efficiency of six phthalic acid esters $\left(10 \mu \mathrm{g} \mathrm{L}^{-1}\right)$ with different amount of sample volume. Extraction conditions: $30 \mathrm{mg}$ of mixed sorbents (15 mg of $\mathrm{Fe}_{3} \mathrm{O}_{4} \mathrm{aMIL}-100$ and $15 \mathrm{mg}$ of $\mathrm{Fe}_{3} \mathrm{O}_{4} \mathrm{a}$ $\mathrm{SiO}_{2}(\mathrm{APT}), 1 \mathrm{~mL}$ of $\mathrm{ACN}$ as elution solvent, $\mathrm{pH} 6.0$, adsorption time $15 \mathrm{~min}$, and desorption time $10 \mathrm{~min}$.

this study, length of desorption time was investigated in the range of 5-25 min. As shown in Fig. S4, $\dagger$ the tested analytes were eluted from adsorbents within $10 \mathrm{~min}$ and the recoveries were slightly decreased when desorption time is longer than $10 \mathrm{~min}$. Therefore, a desorption time of $10 \mathrm{~min}$ was chosen for further experimental work.

3.2.6. Sample volume. Different volume of water samples (5-30 mL) was examined on the extraction efficiency under previous optimized extraction conditions. The best extraction recoveries were obtained when $10 \mathrm{~mL}$ of water sample was used (Fig. 5) for the six analytes. The extraction efficiencies of the tested PAEs were gradually decreased with increment of sample volume from 10 to $30 \mathrm{~mL}$. Large sample volumes might reduce the amount of sorbent particle per unit, which diminished the accessibility of the analytes onto the sorbent surface ${ }^{15} \mathrm{~A}$ sample volume of $10 \mathrm{~mL}$ was therefore selected for the further experimental works.

\subsection{Reusability evaluation}

The reusability of the mixed magnetic sorbents was investigated under optimal conditions for several consecutive MSPE cycles. After each cycle, the mixed sorbents were regenerated by washing twice with $2 \mathrm{~mL}$ of ACN each time. The negative detection of the target analytes in the washing solution indicates the absence of carry-over during the extraction procedure. No obvious changes of the extraction efficiency for the tested analytes were observed within 7 cycles (Fig. S5†). After 7 cycles, the sorbents still demonstrated strong extraction ability for both DEP and DBP, but less extraction efficiency for the rest of the analytes. Then, the prepared mixed adsorbents can be recycled for 7 times for enrichment and extraction of the tested PAEs in water samples.

\subsection{Control of the xenobiotic phthalate contamination}

In the present study, several attempts have been made to minimize the secondary contamination. First, before usage, all solvents were checked for the presence of phthalates. Second, glass flasks and beakers were used during magnetic microspheres synthesis, whereas glass vials, pipettes and glass membranes were used necessarily during sample preparation and analysis. Third, the glassware was thoroughly rinsed with acetone and hexane and then dried at $60{ }^{\circ} \mathrm{C}$ for $6 \mathrm{~h}$, and was finally placed in a furnace oven at $400{ }^{\circ} \mathrm{C}$ for $6 \mathrm{~h}$. Forth, a new DB5-MS capillary column was used for phthalate analysis. The injection port seals, liners, and septa were replaced regularly. As contamination is common issue in phthalate analysis, all efforts were put to minimize the xenobiotic phthalate contamination. We had evaluated the contamination of blank samples, the used blank pure solvent and the GC-MS instrumental blank. The measured values were all below the MDLs. All these results indicated that the xenobiotic phthalate contamination from our laboratory might have little influence on this study.

\subsection{Method validation}

3.5.1. Linearity, method detection limit (MDL), and limit of quantitation (LOQ). The external standard method was used, and calibration curves were constructed with PAEs' concentration in the range of 5.0-5000 $\mu \mathrm{g} \mathrm{L}^{-1}$ for each analyte in hexane. As shown in Table 2, good linearity with coefficients of determination $\left(R^{2}\right)>0.9935$ was obtained for each tested analytes. The MDLs and LOQs were calculated according to Analytical Detection Limit Guidance. ${ }^{21}$ The MDLs were ranged from 0.35 to $0.91 \mu \mathrm{g} \mathrm{L}^{-1}$, and the LOQs were in the range of 1.1-2.9 $\mu \mathrm{g} \mathrm{L}^{-1}$ (Table 2). The repeatability of the developed method, investigated by six parallel extractions of the standard solutions at a concentration level of $10 \mu \mathrm{g} \mathrm{L}^{-1}$, was in the range of 3.5-7.5\% (RSD, $n=6$ ).

3.5.2. Accuracy and precision. To evaluate the accuracy (expressed as recovery) and precision (expressed as RSD), the tested analytes were spiked at 3 fortification levels (1.0, 10.0, and $50.0 \mu \mathrm{g} \mathrm{L}^{-1}$ ) to tap, drinking, and mineral water sample,

Table 2 Linear range, coefficient of determination $\left(R^{2}\right)$, the calculated method detection limits (MDLs) and limits of quantitation (LOQs) for 6 PAEs

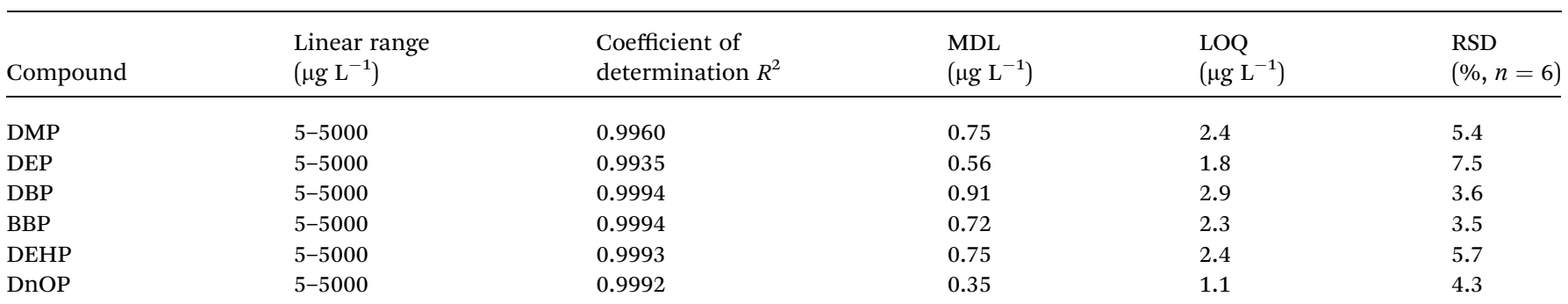


Table 3 Recoveries (\%) and relative standard deviation (RSD, \%) for 6 PAEs in different water samples ${ }^{a}$

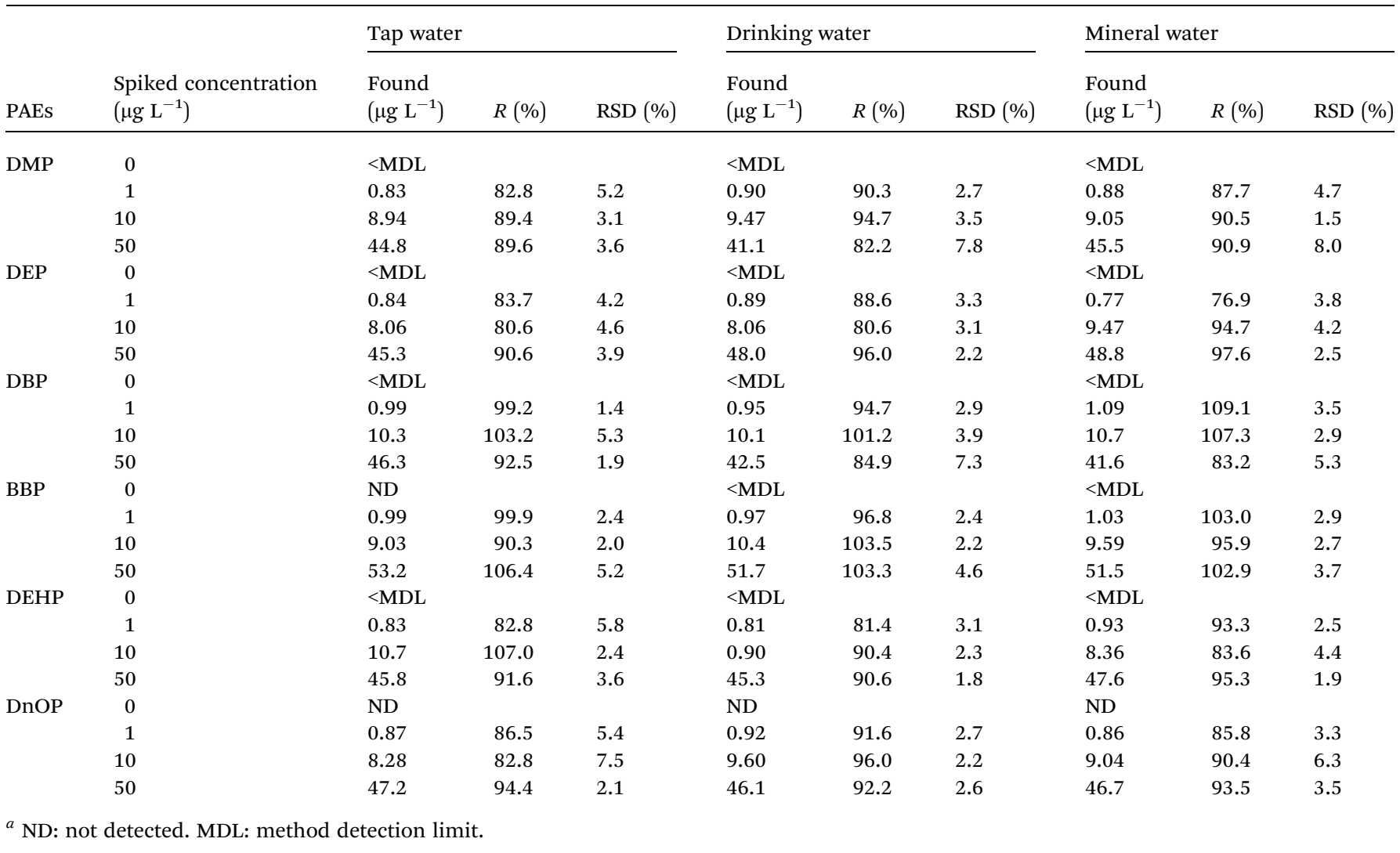

respectively. Then, the samples were vortex-mixed for $30 \mathrm{~s}$ and equilibrated for $10 \mathrm{~min}$ before extraction, which guarantees the full dispersion of the analytes into water. Subsequently, the MSPE procedure was performed as aforementioned in Section 2.4. As shown in Table 3, the mean recoveries for the tested PAEs in tap, drinking, and mineral water samples were ranged from $76.9 \%$ to $109.1 \%$ with RSDs between $1.4 \%$ and $8.0 \%$, respectively. These results indicate that the developed method is appropriate for determination of the six PAEs in tested water samples.

\subsection{Analysis of real samples}

To demonstrate the potential applicability of the developed method, various water samples, including tap, drinking and mineral water were monitored for the tested PAEs. Tap water (not for drinking) was obtained from our laboratory, while drinking and mineral water were purchased from local big market. It has to be noted that DnOP was not detected in any of the monitored samples, whereas DMP, DEP, DBP, BBP, and DEHP were detected in various samples with concentrations being lower than their MDLs (Table 3). The selected ion chromatograms of the tested PAEs in tap water analyzed by the proposed MSPE-GC-MS method are shown in Fig. 6.

\subsection{Method comparison}

The performance parameters of the developed method in terms of extraction time (including adsorption and desorption time), the amount of sorbents and reusability of sorbents were compared with other methods for PAEs analysis. As compiled in Table 4, the total extraction time of the developed method herein was $25 \mathrm{~min}$, which is shorter than that recorded in $\mathrm{Fe} @ \mathrm{SiO}_{2}$-PEI-HPLC-UV (44 $\left.\mathrm{min}\right)^{19}$ and Mag-graphene@ $\mathrm{mSiO}_{2^{-}}$ C18-GC-MS (35 min). ${ }^{22}$ The amount of adsorbents used in this study was lower than that used in $\mathrm{Fe}_{3} \mathrm{O}_{4} @$ @PT-GC-FID method ${ }^{15}$ and Mag-graphene@mSiO ${ }_{2}$-C18-GC-MS method, ${ }^{22}$ and was equal to that used in $\mathrm{Fe}_{3} \mathrm{O}_{4} @$ silica@triblockcopolymer-GC-MS

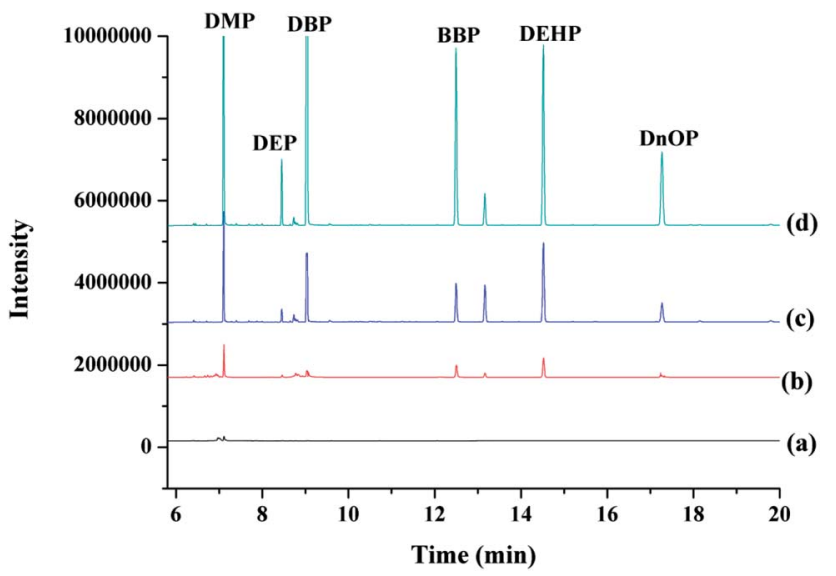

Fig. 6 Typical selected ion chromatogram of six phthalic acid esters in tap water: non-spiked tap water (a), tap water spiked at $1.0 \mu \mathrm{g} \mathrm{L}^{-1}(\mathrm{~b})$, $10.0 \mu \mathrm{g} \mathrm{L}^{-1}$ (c) and $50.0 \mu \mathrm{g} \mathrm{L^{-1 }}$ (d). Extraction conditions: $30 \mathrm{mg}$ of mixed sorbents (15 mg of $\mathrm{Fe}_{3} \mathrm{O}_{4} \mathrm{QMIL}-100$ and $15 \mathrm{mg}$ of $\mathrm{Fe}_{3} \mathrm{O}_{4} \mathrm{a}$ $\mathrm{SiO}_{2}(\mathrm{aPT}), 1 \mathrm{~mL}$ of $\mathrm{ACN}$ as elution solvent, $\mathrm{pH}$ 6.0, adsorption time $15 \mathrm{~min}$, desorption time $10 \mathrm{~min}$, and sample volume $10 \mathrm{~mL}$. 
Table 4 Comparison of the developed method with other reported methods for the analysis of PAEs ${ }^{a}$

\begin{tabular}{|c|c|c|c|c|c|}
\hline Analyte & Method & $\begin{array}{l}\text { Extraction } \\
\text { time (min) }\end{array}$ & $\begin{array}{l}\text { Adsorbent } \\
\text { amount (mg) }\end{array}$ & $\begin{array}{l}\text { Reusability } \\
\text { (times) }\end{array}$ & Ref. \\
\hline DMP DEP DBP BBP DEHP DnOP & Magnetic CTFs/Ni-GC-FID & 25 & 10 & 3 & 1 \\
\hline $\begin{array}{l}\text { DMP DEP DIBP DBP BBP DEHP } \\
\text { DnOP }\end{array}$ & $\begin{array}{l}\mathrm{Fe}_{3} \mathrm{O}_{4} @ \text { silica@triblockcopoly-mer-GC- } \\
\text { MS }\end{array}$ & 20 & 30 & - & 12 \\
\hline DBP DEHP DOA & $\mathrm{Fe}_{3} \mathrm{O}_{4} @ P T-G C-F I D$ & 12 & 100 & - & 15 \\
\hline DMP DEP DBP BBP DEHP DnOP & $\begin{array}{l}\mathrm{Fe}_{3} \mathrm{O}_{4} @ \mathrm{MIL}-100 \text { \& } \mathrm{Fe}_{3} \mathrm{O}_{4} @ \mathrm{SiO}_{2} @ \mathrm{PT}- \\
\mathrm{GC}-\mathrm{MS}\end{array}$ & 25 & 30 & 7 & $\begin{array}{l}\text { This } \\
\text { work }\end{array}$ \\
\hline
\end{tabular}

${ }^{a}$ CTF: Covalent triazine frameworks; GC-FID: gas chromatography-flame ionization detector; ZIF-8: Zeolitic Imidazolate Framework-8; HPLC-DAD: high-performance liquid chromatography-diode array detection; PEI: polyethyleneimine; HPLC-UV: high-performance liquid chromatographyultraviolet detector; DIBP: diisobutyl phthalate; DOA: dioctyl adipate; DPP: diphenyl phthalate; DPIP: diphenyl isophthalate; DCHP: dicyclohexyl phthalate.

method. ${ }^{12}$ In the present study, the synthetic magnetic nanocomposites can be reused for 7 times, which was superior to the previous report. ${ }^{1}$ Several reports ${ }^{\mathbf{1 , 1 2 , 2 2}}$ have recorded poor extraction efficiency of DMP or DEP. In this study, the conjoint magnetic composites ( $\mathrm{Fe}_{3} \mathrm{O}_{4} @ \mathrm{MIL}-100$ and $\left.\mathrm{Fe}_{3} \mathrm{O}_{4} @ \mathrm{SiO}_{2} @ \mathrm{PT}\right)$ used here significantly improve the extraction efficiency of both DMP and DEP.

\section{Conclusions}

In the present work, two types of magnetic nanocomposites ( $\mathrm{Fe}_{3} \mathrm{O}_{4} @ \mathrm{MIL}-100$ and $\mathrm{Fe}_{3} \mathrm{O}_{4} @ \mathrm{SiO}_{2} @ \mathrm{PT}$ ) were successfully prepared and characterized, and used as efficient mixed sorbents for the extraction and enrichment of 6 PAEs (DMP, DEP, DBP, BBP, DEHP, and DnOP) in water samples, owing to $\pi-\pi$ and the hydrophobic interactions. Samples were quantified using GC-MS. The mixed sorbents exhibited good chemical stability and reusability (at least 7 times). Under the optimal conditions, satisfactory extraction efficiencies and high sensitivities were obtained for all tested analytes. The developed method was successfully applied for monitoring real water samples. The developed method is simple, rapid and effective, and may be extrapolated for analysis of other hydrophobic aromatic compounds at trace levels in water samples.

\section{Conflicts of interest}

The authors have declared no conflicts of interest.

\section{Acknowledgements}

This work was supported by the Special Program for Basic Work of the Ministry of Science and Technology of China (2013FY110100), and Guangxi Innovation-driven Development Project (AA17204043-2).

\section{References}

1 Z. J. Yan, M. He, B. B. Chen, B. Gui, C. Wang and B. Hu, J. Chromatogr. A, 2017, 1525, 32-41.
2 X. M. Liu, Z. W. Sun, G. Chen, W. W. Zhang, Y. P. Cai, R. M. Kong, X. Y. Wang, Y. R. Suo and J. M. You, J. Chromatogr. A, 2015, 1409, 46-52.

3 D. M. Xu, X. J. Deng, E. H. Fang, X. H Zheng, Y. Zhou, L. Y. Lin, L. P. Chen, M. Wu and Z. Q. Huang, J. Chromatogr. A, 2014, 1324, 49-56.

4 V. Fernández-González, C. Moscoso-Pérez, S. MuniateguiLorenzo, P. López-Mahía and D. Prada-Rodríguez, Talanta, 2017, 162, 648-653.

5 M. Behzadi, E. Noroozian and M. Mirzaeia, RSC Adv., 2014, 4, 50426-50434.

6 V. L. Turco, G. Di Bella, A. G. Potorti, M. R. Fede and G. Dugo, Eur. Food Res. Technol., 2015, 240, 451-458.

7 Q. Xu, X. Y. Yin, S. Y. Wu, M. Wang, Z. Y. Wen and Z. Z. Gu, Microchim. Acta, 2010, 168, 267-275.

8 C. Sablayrolles, M. Montréjaud-Vignoles, D. Benanou, L. Patria and M. Treilhou, J. Chromatogr. A, 2005, 1072, 233-242.

9 H. Amanzadeha, Y. Yamini, M. Moradi and Y. A. Asl, J. Chromatogr. A, 2016, 1465, 38-46.

10 S. Lirio, C. W. Fu, J. Y. Lin, M. J. Hsu and H. Y. Huang, Anal. Chim. Acta, 2016, 927, 55-63.

11 X. L. Song, Y. Chen, J. P. Yuan, Y. J. Qin, R. S. Zhao and X. Wang, J. Chromatogr. A, 2016, 1468, 17-22.

12 M. Xu, M. H. Liu, M. R. Sun, K. Chen, X. J. Cao and Y. M. Hu, Talanta, 2016, 150, 125-134.

13 X. F. Chen, N. Ding, H. Zang, H. Yeung, R. S. Zhao, C. G. Cheng, J. H. Liu and T. W. Dominic Chan, J. Chromatogr. A, 2013, 1304, 241-245.

14 A. Mehdinia, N. Khodaee and A. Jabbari, Anal. Chim. Acta, 2015, 868, 1-9.

15 E. Tahmasebi, Y. Yamini, M. Moradi and A. Esrafili, Anal. Chim. Acta, 2013, 770, 68-74.

16 X. L. Cao, G. Y. Liu, Y. X. She, Z. J. Jiang, F. Jin, M. J. Jin, P. F. Du, F. N. Zhao, Y. X. Zhang and J. Wang, RSC Adv., 2016, 6, 113144-113151.

17 M. E. S. Synaridou, V. A. Sakkas, C. D. Stalikas and T. A. Albanis, J. Chromatogr. A, 2014, 1348, 71-79.

18 S. X. Zhang, H. Y. Niu, Y. Q. Cai and Y. L. Shi, Anal. Chim. Acta, 2010, 665, 167-175. 
19 Q. X. Zhou, Z. W. Zheng, J. P. Xiao, H. L. Fan and X. Y. Yan, Anal. Bioanal. Chem., 2016, 408, 5211-5220.

20 H. Li, Z. J. Jiang, X. L. Cao, H. Su, H. Shao, F. Jin, L. F. Zheng, A. M. Abd El-Aty and J. Wang, Chromatographia, 2018, 81, 359-364.

21 Analytical Detection Limit Guidance \& Laboratory Guide for Determining Method Detection Limits, Wisconsin
Department of Natural Resources Laboratory Certification Program, 1996, http:/dnr.wi.gov/regulations/labcert/ documents/guidance/-lodguide.pdf.

22 D. N. Huang, X. Y. Wang, C. H. Deng, G. X. Song, H. F. Cheng and X. M. Zhang, J. Chromatogr. A, 2014, 1325, 65-71. 